\title{
ГЛИНИСТОЕ ВЕЩЕСТВО В КЕМБРИЙКИХ ПОРОДАХ ЛАТВИИ
}

Глинистое вещество в отложениях кембрия Латвии, во-первых, является породообразующим в собственно глинистых породах, во-вторых, играет значительную роль в цементации песчаников и алевролитов.

Изучение кембрийских глин и глинистого цемента песчаников и алевролитов производилось с помощью комплекса методов (макроскопическое изучение глин по керновому материалу, описание шлифов, изучение фракции меньше 0,001 мм с помощью иммерсионного, термического, рентгеноструктурного и химического анализов). Анализы произведены в Центральной лаборатории Управления геологии Латвийской ССР, кроме рентгеноструктурного анализа, который проведен в минералогическом кабинете Тартуского государственного университета под руководством К. Утсала.

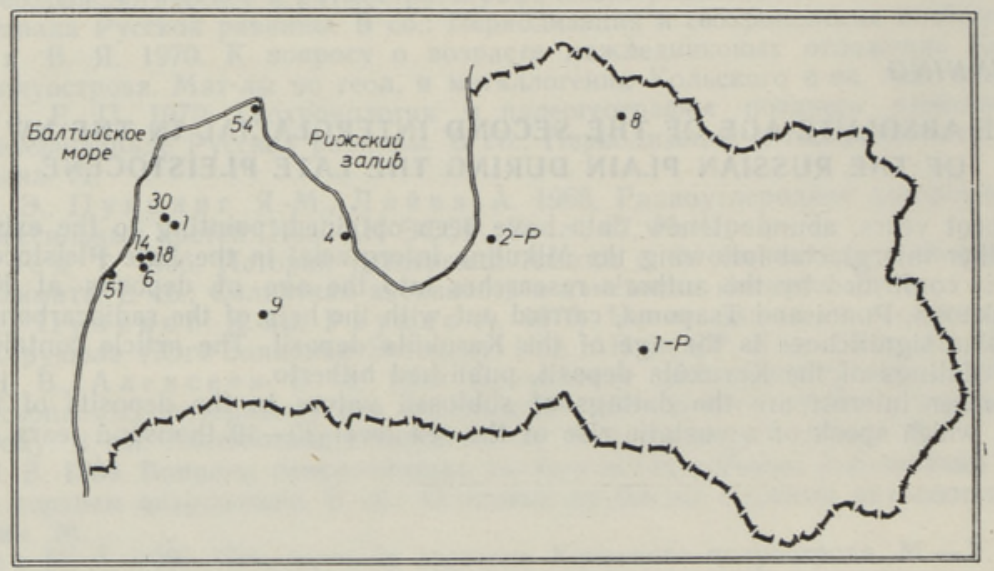

Схема расположення буровых скважин.

1 - Пилтене, 30 - Пилтене, 6 - Адзе, 18 - Стирнас, 14 - Плиенкалны, 51 - Павнлоста, 9 - Куйли, 2-P - Инчукалнс, $8-$ Стренчи, 1 - $P$ - Пля-

Полный комплекс анализов сделан выборочно по 30 пробам, неполный (термический анализ, микроскопическое изучение) - по 152 пробам. Систематически послойно изучались кембрийские глины, а также цемент песчаников и алевролитов из скв. Павилоста. Менее детально изучены разрезы скважин Пилтене № 1, Пилтене № 30, Адзе, Стирнас, Энгуре, Плиенкалны, Куйли, Инчукалнс, Плявиняс, Стренчи (рисунок). 
В работе использована с некоторыми изменениями стратиграфическая схема кембрия Латвии Э. Лиелдиена и А. Фридрихсоне (1968). Мы не употребляем используемых авторами названий «кибартайская свита» для отложений среднего кембрия и «тискреская свита» для пород срєднего-верхнего (?) кембрия, поскольку первый термин некоторыми литовскими геологами применяется для обозначения нижнекембрийских отложений (Сакалаускас, 1966), а несопоставимость отложений тискреской свиты с отложениями среднего-верхнего (?) кембрия доказана эстонскими геологами (Мардла и др., 1968). Автор пользовался укоренившимся в геологической литературе термином «пиритаская свита» для обозначения отложений с Volborthella tenuis Schm.

Глинииты е породы составляют значительную часть разреза кембрия на территории республики, в особенности его нижнего отдела. Содержание глин в составе лонтоваской свиты колеблется от 28 до $100 \%$, пиритаская свита содержит от 20 до $66 \%$ глинистых пород. В составе отложений среднего кембрия их несколько меньше (от 7 до $50 \%$ ). Глинистость разреза среднего-верхнего (?) кембрия не превышает $10 \%$.

Глинам кембрия свойственна зеленовато-серая, реже буровато-серая или буровато-коричневая с фиолетовым оттенком окраска, обусловленная значительной примесью минералов, содержащих окисное или закисное железо: глауконита, гидроокислов железа, пирита, сидерита, а также хлорита и органического вещества. Структура глин обычно алевропелитовая, реже псаммоалевропелитовая.

Гидродинамика мелководного моря и жизнедеятельность илоедов образовали характерную для нижнекембрийских алеврито-глинистых пород текстуру «kraksten». Кроме того, отмечены линзовидно-слоистые, торизонтально- и наклонно-слоистые текстуры.

Алевритовая примесь в глинах составляет $25-45 \%$. В составе алевритовых частиц доминируют неокатанные, корродированные обломки кварца. В качестве незначительной примеси присутствуют слюды, калиевые полевые шпаты, акцессорные минералы. К терригенным компонентам местами присоединяется детрит беззамковых брахиопод.

Преобладающим глинистым минералом среди глинистых пород кембрия является диоктаэдрическая гидрослюда типа $1 \mathrm{Md}$, которая составляет от 50 до $95 \%$ фракции меньше 0,001 мм. Она значительно гидратизирована, что выражается в расширении базального межплоскостного расстояния (001) до 10,25 А. Гидрослюда аллотигенного и аутигекного происхождения. Аллотигенная гидрослюда представляет собой продукт размыва глинистых пород более древних свит и коры выветривания докембрийских магматических пород. В шлифах она характеризуется зеленовато-бурой окраской и высоким двупреломлением (желтые цвета интерференции). Показатель преломления изменяется в зависимости от степени гидратизации. Гидрослюда имеет чешуйчатое строение, и в результате процессов уплотнения базальные плоскости ее ориентированы параллельно слоям. О присутствии гидрослюд свидетельствует целый ряд рефлексов на дифрактометрических кривых $(10,09 ; 4,98 ; 4,48$; $3,34 ; 2,583 ; 1,505 \AA$ и т. д., см. табл. 1$)$.

Термические кривые кембрийских глин характеризуются тремя эндоэффектами. Первый эндоэффект в интервале $120-160^{\circ} \mathrm{C}$, связанный с удалением адсорбированной воды, обычно меньше второго пика с максимумом в интервале 520 - $560^{\circ}$, обусловленного выделением конституционной воды гидрослюд. Третий эндотермический пик в интервале $870-880^{\circ}$ свидетельствует о разрушении кристаллической решетки гидрослюд (Иванова, 1961).

4 ENSV TA Toimetised $\mathrm{K} * \mathrm{G}-31971$ 
Аутигенная гидрослюда глауконитового типа является продуктом раннего диагенеза (Копелиович, 1965; Теодорович, 1962). Она особенно обогащает породы нижнего кембрия и наблюдается как в тонкодисперсном виде, так и в виде скоплений частиц размером до $0,2 \mathrm{м \mu}$.

Глауконит обогащает глинистые и песчано-алевритовые отложения нижнего кембрия, определяя глауконитовую геохимическую фацию этих пород. Последняя в средней части разреза балтийской серии переходит в гидрогетитовую геохимическую фацию литогенеза, которая выражается накоплением прослоя бурого оолитового железняка непостоянной мощности на территории Польско-Литовской синеклизы.

Вторым наиболее распространенным минералом глин кембрия является каолинит, составляющий в некоторых прослоях до $50 \%$ глинистой массы. Каолинитом обогащена кровля нижнего кембрия, а также подошвенные слои среднего и верхнего кембрия. Обычно каолинитовая примесь в глинах не превышает $10-20 \%$ глинистых минералов.

$\mathrm{O}$ каолинитовой примеси свидетельствуют рефлексы 7,18 и $3,55 \AA$ на дифрактограммах, полностью исчезающие после прокаливания образца в течение двух часов при температуре $500^{\circ}$.

В термограммах присутствие каолинита сказывается углублением второго эндоэффекта и наличием экзоэффекта в интервале температур $920-960^{\circ}$.

Почти во всех образцах кембрийских глин рентгеноструктурный анализ доказывает (рефлексы 14,$25 ; 7,10 ; 3,55 ; 1,54 \AA$ ) присутствие хлорита. После обработки образца $10 \%$-ной $\mathrm{HCl}$ эти рефлексы (в случає отсутствия каолинитовой примеси) исчезают. Хлорит богат железом, о чем свидетельствует слабость рефлексов первого и третьего порядков отражения (Грим, 1959). В случае небольших количеств хлорита его присутствие термическим анализом диагностируется слабо.

Хлорит в глинистых породах кембрия имеет разный генезис. Во-первых, он представляет собой продукт изменения обломочного биотита (это хорошо прослеживается по шлифам глинистых пород). С другой стороны, хлорит образовался за счет богатых железом, алюминием и кремнием растворов во время осадконакопления и диагенеза. Об этом свидетельствует обогащение глинистого вещества хлоритом в прослоях глин вблизи бурого оолитового железняка, который залегает в средней части пиритаской свиты на большой территории Польско-Литовской синеклизы. Содержание хлорита в глинах этой части разреза по данным дифрактометрического анализа достигает $25 \%$ всех глинистых минералов (табл. 1). Усиленно приносимое железо в бассейн этого времени в зависимости от физико-химической обстановки среды входило в состав бурого железняка или хлорита (Теодорович, 1962). Безусловно, не исключается возможность дополнения хлоритового компонента глинистого вещества кластогенным путем, подобно гидрослюдам.

В некоторых образцах глин из разреза кембрия, залегающего на менее значительных глубинах (скв. Инчукалнс, Стренчи), по данным дифрактометрического анализа обнаружена примесь смешанно-слойных фаз типа монтмориллонит-гидрослюда с базальным рефлексом 11,0-11,3 Ӓ, который после насыщения образца глицерином увеличивает свое значение до $15 \AA$.

Bсе дифрактометрические кривые кембрийских глин указывают на присутствие тонкодисперсного кварца в составе мелкопелитовой фракции.

Химические анализы глин подтверждают преобладание в их составе гидрослюд, так как содержание $\mathrm{K}_{2} \mathrm{O}$ в составе фракции меньше 0,001 ㅆ 
ב⿱艹

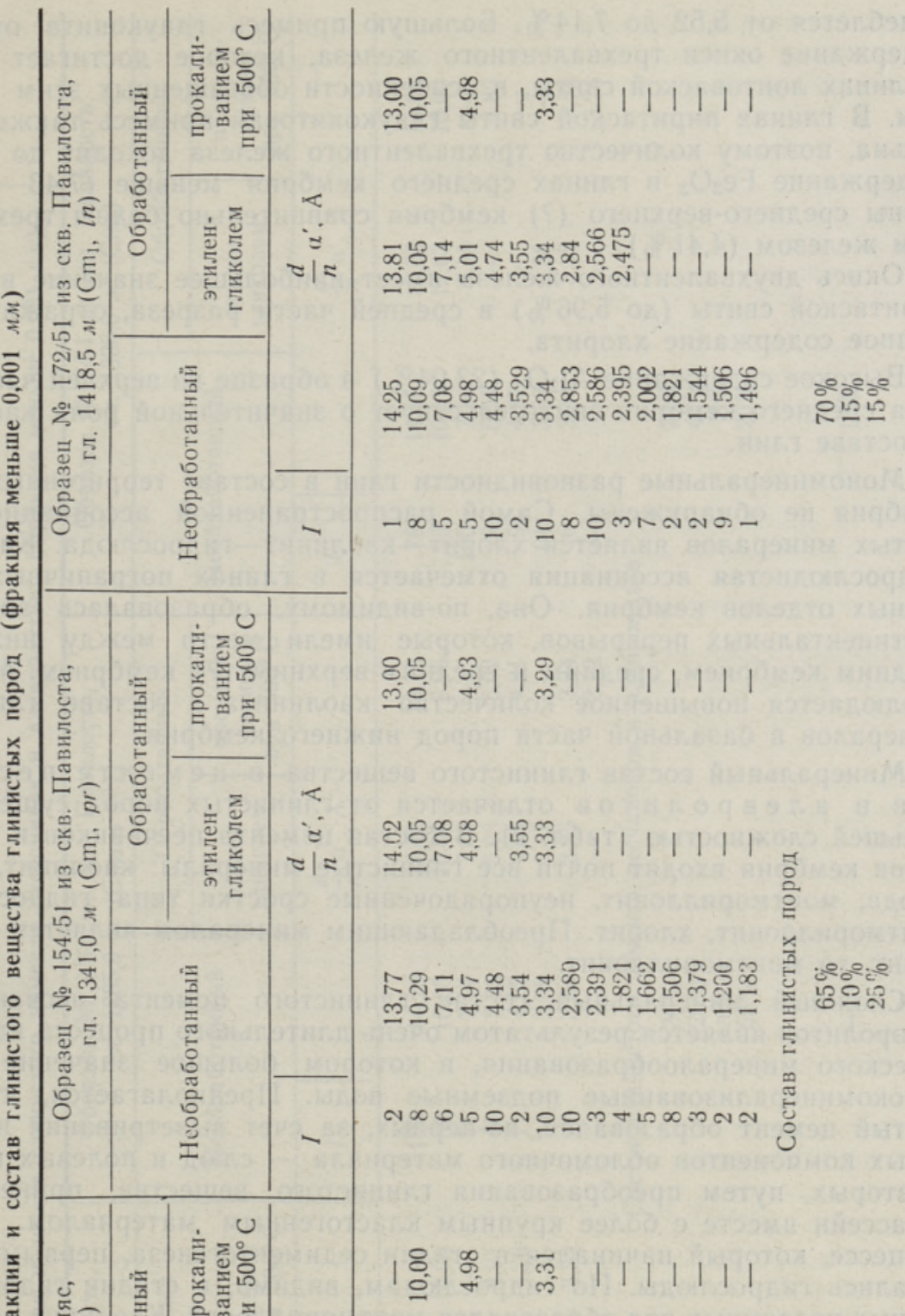


колеблется от 5,52 до $7,14 \%$. Большую примесь глауконита отражает содержание окиси трехвалентного железа, которое достигает 18,77\% в глинах лонтоваской свиты, в особенности обогащенных этим минералом. В глинах пиритаской свиты глауконитовая примесь также значительна, поэтому количество трехвалентного железа доходит до $12,81 \%$. Содержание $\mathrm{Fe}_{2} \mathrm{O}_{3}$ в глинах среднего кембрия меньше $(7,43-9,43 \%)$, глнны среднего-верхнего (?) кембрия сравнительно бедны трехвалентным железом $(4,41 \%)$.

Окись двухвалентного железа имеет наибольшее значение в глинах пиритаской свиты (до 5,96\%) в средней части разреза, отражая повышенное содержание хлорита.

Высокое содержание $\mathrm{Al}_{2} \mathrm{O}_{3}(23,94 \%)$ в образце из верхней части разреза среднего кембрия свидетельствует о значительной роли каолинита в составе глин.

Мономинеральные разновидности глин в составе терригенных пород кембрия не обнаружены. Самой распространенной ассоциацией глинистых минералов является хлорит-каолинит-гидрослюда. Каолинит-гидрослюдистая ассоциация отмечается в глинах пограничных слоев разных отделов кембрия. Она, по-видимому, образовалась во время континентальных перерывов, которые имели место между нижним и средним кембрием, средним и средним-верхним (?) кембрием. Местами наблюдается повышенное количество каолинита в составе глинистых минералов в базальной части пород нижнего кембрия.

Минеральный состав глинистого вещества в цемен те песчани ков и а л е в оли тов отличается от глинистых пород существенно большей сложностью (табл. 2). В состав цемента песчаников и алевролитов кембрия входят почти все глинистые минералы: каолинит, гидрослюда, монтмориллонит, неупорядоченные сростки типа гидрослюдамонтмориллонит, хлорит. Преобладающим минералом является то каолинит, то монтмориллонит.

Сложный минеральный состав глинистого цемента песчаников и алевролитов является результатом очень длительного процесса катагенетического минералообразования, в. котором большое значение имели высокоминерализованные подземные воды. Предполагается, что гли. нистый цемент образовался, во-первых, за счет выветривания неустойчивых компонентов обломочного материала - слюд и полевых шпатов, во-вторых, путем преобразования глинистого вещества, принесенного в бассейн вместе с более крупным кластогенным материалом. В этом процессе, который начинался в стадии седиментогенеза, первыми образовались гидрослюды. По гидрослюдам, видимо, в стадии гидрокарбонатных подземных вод образовался монтмориллонит. Каолинит является последним членом процесса глинообразования в цементе песчаников и алевролитов. Он, вероятно, образовался в зоне высокоминерализованных подземных вод хлор-кальциевого типа. Хлорит в песчаниках н алевролитах является конечным продуктом преобразования биотита.

Из изложенного выше следует, что различия в минеральном составе глинистых пород и глинистого цемента алевролитов и песчаников являются результатом различной фнзико-химической обстановки во время постседиментационных изменений. Ограниченные фильтрационные свойства глин способствовали сохранению их первичного минерального состава, который был создан во время выветривания материнских пород, переноса и седиментогенеза (гидрослюда, каолинит) и дополнен минералами, имеющими постседиментационный генезис (глауконит, частично хлорит). Хорошие фильтрационные способности песчаников и 


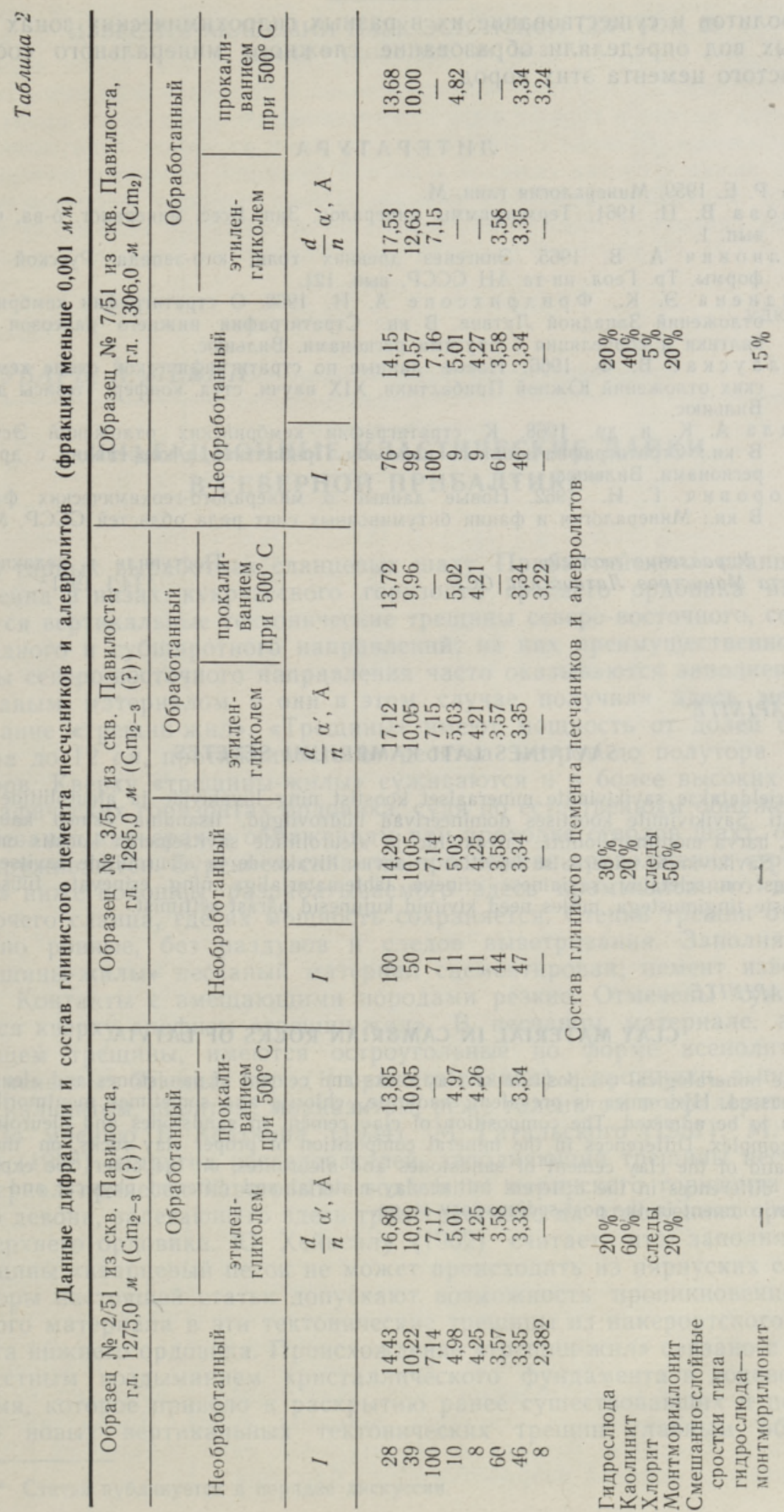


аліевролитов и существование их в разных гидрохимических зонах подземных вод определяли образование сложного минерального состава глинистого цемента этих пород.

\title{
ЛИ ТЕ Р А Т Р А
}

Г р и м Р. Е. 1959. Минералогия глин. М.

Ив а н о в а В. П. 1961. Термограммы минералов. Зап. Всес. минералог. о-ва, ч. ХС, вып. 1.

Копелиович А. В. 1965. Эпигенез древних толщ юго-запада Русской платформы. Тр. Геол. ин-та АН СССР, вып. 121.

Лиелдиена Э. К., Фридрихсоне А. И. 1968. О стратиграфии кембрийских отложений Западной Латвии. В кн.: Стратиграфия нижнего палеозоя Прибалтики и коррелящия с другими регионами. Вильнюс.

Сакалауска с В. Ф. 1966. Новые данные по стратиграфической схеме кембрийских отложений Южной Прибалтики. XIX научн. студ. конфер. (тезисы докл.). Вильнюс.

М ардла А. К. и др. 1968. К стратиграфии кембрийских отложений Эстонин. В кн.: Стратиграфия нижнего палеозоя Прибалтики и корреляция с другими регионами. Внльнюс.

Теодорович Г. И. 1962. Новые данные о минералого-геохимических фациях. В кн.: Минералогия и фации битуминсзных свит ряда областей СССР. М.

\author{
Управление геологии \\ Совета Министров Латвийской ССР
}

Поступила в редакцию

14/I 1971

\section{ILGA APINITE}

\section{SAVIAINES LATI KAMBRIUMI SETETES}

Kirjeldatakse savikivimite mineraalset koostist ning liivakivide ja aleuroliitide savitsementi. Savikivimite koostises domineerivad hüdrovilgud, lisandina esineb kaoliniiti, kloriiti, harva montmorilloniiti. Liivakivide ja aleuroliitide savitsemendi koostis on keerukam. Savikivimite mineraalse koostise erinevus liivakivide ja aleuroliitide savitsemendi koostisest on seletatav saviainese erineva lähtematerjaliga ning erinevate füüsikaliskeemiliste tingimustega, milles need kivimid kujunesid pärast settimist.

\section{ILGA APINITE}

\section{CLAY MATERIAL IN CAMBRIAN ROCKS OF LATVIA}

The mineralogical composition of clay rocks and cement of sandstones and aleurolites is discussed. Hydromica is prevalent; kaolinite, chlorite and sometimes montmorillonite happen to be admixed. The composition of clay cement in sandstones and aleurolites is more complex. Differences in the mineral composition of proper clay rocks, on the one hand, and of the clay cement of sandstones and aleurolites, on the other, are explained by the differences in the different initial clay material and different physical and chemical environment in the post-sedimentary stage. 